\title{
ESTUDO DA CIÊNCIA DA EDUCAÇÃO FUNDAMENTADA NA INTERDISCIPLINARIDADE POR OLGA POMBO: UM ESTUDO DE REVISÃO
}

\author{
ESTUDIO DE LA CIENCIA DE LA EDUCACIÓN BASADA EN LA \\ INTERDISCIPLINARIEDAD POR OLGA PALOMA: UN ESTUDIO DE REVISIÓN
}

\author{
STUDY OF THE SCIENCE OF EDUCATION BASED ON INTERDISCIPLINARITY BY \\ OLGA POMBO: A REVIEW STUDY
}

\author{
Patrícia MEDINA ${ }^{1}$ \\ Maria Leda Melo Lustosa PEREIRA ${ }^{2}$ \\ José Eudacy Feijó de PAIVA ${ }^{3}$
}

RESUMO: Trata-se de revisão sistemática da literatura, com objetivo de verificar como as ideias de interdisciplinaridade formuladas pela epistemóloga portuguesa Olga Pombo apresentam-se nas teses de doutorado publicadas no catálogo de teses e dissertações da Coordenação de Aperfeiçoamento de Pessoal de Nível Superior (CAPES), no período de 2015 a 2017. O corpus final foi formado de 28 teses, sendo onze em Educação, oito em Ciência da Informação e as demais nas áreas de Saúde, Desenvolvimento e Meio Ambiente. Neste estudo verificou-se que a interdisciplinaridade retratada corrobora o conceito defendido pela autora em relação a "manifestação de transformação epistemológica em curso".

PALAVRAS-CHAVE: Interdisciplinaridade. Olga Pombo. Integração de saberes.

RESUMEN: Es una revisión sistemática de la literatura, con el fin de comprobar cómo las ideas de la interdisciplinariedad formulan por la epistemóloga Portugués Olga Pombo presentar las tesis doctorales publicadas en el catálogo de tesis y disertaciones el Coordenação de Aperfeiçoamento de Pessoal de Nível Superior (CAPES), durante el período 2015-2017. El corpus fue formadas 28 tesis, siendo once en ocho educación en Ciencias de la información y la otra en las áreas de salud, el desarrollo y el medio ambiente. En este estudio se encontró que la interdisciplinariedad retratada corrobora el concepto defendido por el autor en relación con "manifestación de transformación epistemológica en marcha".

PALABRAS CLAVE: Interdisciplinariedad. Olga Pombo. Integración de los conocimientos

${ }^{1}$ Universidade Federal do Tocantins (UFT), Palmas - TO - Brasil. Professora Doutora Ajunta da Universidade Federal do Tocantins nos cursos de Pedagogia e Mestrado Profissional Interdisciplinar Prestação Jurisdicional e Direitos Humanos em convênio com Escola da Magistratura do Tocantins. Coordenadora do Programa de Educação Não Escolar da UFT. Coordenadora do Curso de Pedagogia da UFT. Doutora em Educação: Cultura e Processos Educacionais. ORCID: http://orcid.org/0000-0003-2110-1989. E-mail: patriciamedina@uft.edu.br ${ }^{2}$ Universidade Federal do Tocantins (UFT) em parceria com Escola Superior da Magistratura Tocantinense (ESMAT), Palmas - TO - Brasil. Mestranda no Mestrado Profissional Interdisciplinar em Prestação Jurisdicional e Direitos Humanos. ORCID: http://orcid.org/0000-0001-7005-6016. E-mail: ledamlustosa@uol.com.br

${ }^{3}$ Universidade Federal do Tocantins (UFT) em parceria com Escola Superior da Magistratura Tocantinense (ESMAT), Palmas - TO - Brasil. Mestrando no Mestrado Profissional Interdisciplinar em Prestação Jurisdicional e Direitos Humanos. ORCID: http://orcid.org/0000-0002-2017-3713. E-mail: paiva@tre-to.jus.br

RIAEE - Revista Ibero-Americana de Estudos em Educação, Araraquara, v. 14, n. 4, p. 2287-2300, out./dez., 2019. e-ISSN: 1982-5587. DOI: https://doi.org/10.21723/riaee.v14i4.12113 
ABSTRACT: It is a systematic review of the literature, in order to check how the ideas of interdisciplinarity formulated by the Portuguese epistemology Olga Pombo been presented in doctoral theses published in the catalog of theses and dissertations the Coordination of Improvement of Higher Level Personnel (CAPES), during the period from 2015 to 2017, The corpus was formed 28 theses, being eleven in eight Education in information science and the other in the areas of health, development and the environment. In this study it was found that the interdisciplinarity portrayed corroborates the concept advocated by the author in relation to "manifestation of epistemological transformation underway".

KEYWORDS: Interdisciplinarity. Olga Pombo. Integration of knowledge.

\section{Introdução}

A abordagem contextual dos conceitos de interdisciplinaridade, integrações de saberes fundamentados nas obras da autora Olga Pombo foram referendados nas teses analisadas e serão mencionados nesta pesquisa como fontes primárias, pois o que se busca é apresentar uma revisão sistemática de literatura sem fazer inferências sobre o contexto em que o termo aparece citado nas teses objeto de análise, uma vez que podem ser consultadas também as referências primárias de Olga Pombo.

Trata-se então de um estudo de revisão sistemática de literatura visando solucionar uma dúvida científica em contraposição à busca aleatória e voluntariosa de uma revisão bibliográfica típica da revisão tradicional que, neste caso, foi substituída por critérios e processamento constituindo, por isso, num procedimento útil para identificação de temas que necessitam de estudo e discussões mais aprofundados, orientando a definição do objeto de investigação e os argumentos. Por tais características, adotou-se o procedimento para responder ao seguinte questionamento: como as ideias de interdisciplinaridade formuladas pela epistemóloga portuguesa Olga Pombo tem se apresentado nas pesquisas brasileiras?

\section{Percurso Metodológico}

Este estudo caracteriza-se como uma revisão sistemática de conteúdo, a fim de descrever o contexto da interdisciplinaridade em teses do banco de teses da Coordenadoria de Aperfeiçoamento de Pessoal da Educação Superior (CAPES). Optou-se por essa base de dados por se tratar de veículo de professores e alunos da pós-graduação de todo o país, desde 2006, de diferentes áreas do conhecimento, defendidas desde 1987 em instituições brasileiras ou por pesquisadores e estudantes brasileiros em universidades estrangeiras. 
Para a seleção das teses efetuou-se a busca no banco de dados utilizando-se os descritores "interdisciplinaridade" e "Olga Pombo" em busca realizada no dia 16 de setembro de 2018. Selecionados os descritores na barra de dados de busca do painel de informações quantitativas (teses e dissertações) obteve-se 8419 documentos como resultados. Após, foram considerados os parâmetros limitadores da busca inicial, utilizando-se, da ferramenta: refinar meus resultados, tipo: doutorado (tese); ano: 2015, 2016 e 2017, língua português. Para esta segunda busca foram encontrados 456 resultados para Olga Pombo; interdisciplinaridade. Destes, foram excluídas 132 teses que não estavam disponíveis na íntegra para formato online.

Foram perscrutadas as 324 teses restantes com vistas a encontrar os recém mencionados descritores; preencheu-se, no formulário elaborado pelos autores, os campos básicos para a identificação do texto em análise (número de ordem, título e autor), assinalando, ainda, em cada tese a citação feita à referida autora. Houve 296 casos em que a palavra pombo, não correspondia ao descritor "Olga Pombo", mas à ave (pombo) ou como parte de uma palavra, inserida no corpo da pesquisa, como também a palavra “interdisciplinaridade”, utilizada por outros autores. Após a aplicação dos critérios de inclusão e exclusão, restaram um corpus de 28 teses, que atenderam os critérios pré-selecionados inicialmente para a amostra, sendo estas catalogadas e retirados todas as citações existentes no contexto de cada capítulo, dada a sua aderência ao tema abordado, conforme demonstrado no gráfico 1.

Gráfico 1 - Demonstrativo: resultado percurso metodológico aplicado à revisão sistemática, descritores: interdisciplinaridade e Olga Pombo, Teses Capes, 2015-2017.

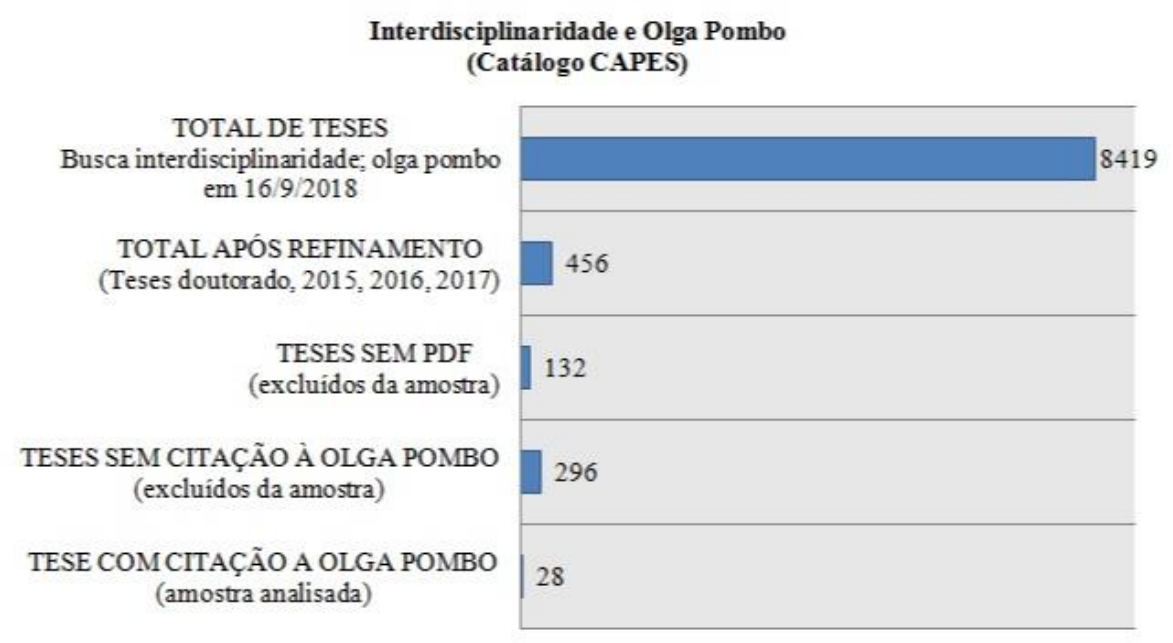

Fonte: catálogo CAPES, 2015/2017

RIAEE - Revista Ibero-Americana de Estudos em Educação, Araraquara, v. 14, n. 4, p. 2287-2300, out./dez., 2019. e-ISSN: $1982-5587$. 
Este percurso metodológico permitiu constatar que, entre as 324 teses a partir dos descritores e dos critérios de inclusão e/ou exclusão indicados, 28 teses abordavam interdisciplinaridade a partir de Olga Pombo. Ou seja, 6\% da amostra estudada.

\section{Resultados e discussão}

A avaliação crítica consistiu na leitura integral de todas as teses selecionados, que reuniram e sistematizaram as informações extraídas de cada um dos textos, no compartilhamento dos apontamentos extraídos na forma de citações diretas entre os coautores da revisão e na identificação do percentual de textos da amostra que passamos a demonstrar. Os resultados foram sistematizados de maneira a identificar os sentidos atribuídos à interdisciplinaridade tendo como referência Olga Pombo no contexto das pesquisas realizadas pelos autores das teses pesquisadas.

As áreas de pesquisa que aplicaram as ideias de interdisciplinaridade de Olga Pombo que mais se destacaram foram: Educação, Enfermagem, Desenvolvimento e Meio Ambiente, Ensino em Biociências e Saúde e Ciência da Informação. Os autores buscaram integrar os saberes de diferentes formas (interdisciplinar, multidisciplinar, transdisciplinar, pluridisciplinar), no entanto, compartilham o entendimento conceitual de Olga Pombo, à respeito da interdisciplinaridade, integrando-a no campo de pesquisa como: na formação do professor, na iniciação à docência, na pós - graduação, na educação ambiental, nas metodologias, no currículo e nos fundamentos interdisciplinar.

Soares (2016) aponta a composição de um cenário com "elementos históricos, interligados ou isolados", que podem ser aproximar do termo interdisciplinaridade como sendo algo que "ninguém sabe o que é isso", pois em "rigor, é impossível falar de interdisciplinaridade porque ninguém sabe o que é". Segundo ele, Pombo toma a 'interdisciplinaridade como um conceito quase mágico'. (SOARES, apud POMBO, 2016, p. 19). Ideia compartilhada no estudo de Soares (2016) que se refere a interdisciplinaridade defendida por Pombo como sendo:

[...], a palavra interdisciplinaridade é invocada para justificar abordagens pedagógicas, metodológicas e ideias acerca do comportamento ético, político, social, cultural e mental do homem no mundo, "quando, simplesmente, nos confrontamos com os limites do nosso conhecimento" (SOARES apud POMBO, 2016, p. 20).

Soares (2016), ressalta que o interesse por investigar os sentidos atribuídos pelos professores para a integração disciplinar, tem a ver como o modo de Pombo perceber os 
docentes "são os professores que, por sua iniciativa, vêm realizando, com uma frequência crescente, experiências de ensino que visam alguma integração dos saberes disciplinares e implicam algum tipo de trabalho de colaboração entre duas ou mais disciplinas". (SOARES apud POMBO, 2016, p. 20).

Neste contexto, a interdisciplinaridade está relacionada a linguagem acessível a todos os saberes, desmistificando a linguagem estritamente técnica para partilhar com outras áreas, tornando o conhecimento acessível a todos os campos do conhecimento corroborando com o intento desta pesquisa que é identificar se a interdisciplinaridade vem sendo utilizada no campo da pesquisa cientifica como sendo algo integrador entre os diversos campos do saber, compartilhado por uma linguagem interdisciplinar, capaz de alcançar diversas áreas do conhecimento, ou seja, assim como se apresentam as principais contribuições de Olga Pombo quanto aos conceitos e fundamentos da interdisciplinaridade defendida pela autora em suas obras originárias.

\section{Conceptualização de interdisciplinaridade na visão de Olga Pombo estudados pelos autores das teses}

Interdisciplinaridade é palavra de conceito multidimensional e ambíguo, sendo um assunto de extensa bibliografia. Estudada tanto por teóricos, educadores e pesquisadores para compreensão e efetivação desta prática (NISENBAUM, 2017, p. 37).

A respeito do uso do termo interdisciplinaridade, vale o registro histórico apontado por Santos (2017):

O termo 'interdisciplinaridade' sobreveio na década de 1960, quando a Organização das Nações Unidas para a Educação, a Ciência e a Cultura (UNESCO) passou a utilizá-lo como um de seus atributos, como uma característica de sua atuação como organização mundial. A partir disso, houve iniciativas tanto no campo de ensino quanto no campo científico, no sentido de aprofundar as reflexões sobre a interdisciplinaridade, incitando, por exemplo, a formulação de projetos visando combater a especialização, como o "Centro de Investigação Interdisciplinar em Ciências Humanas", o qual teve o empreendimento da UNESCO e a autoria de Georges Gusdorf. (SANTOS apud POMBO, 2017, p. 69).

Nisenbaum (2017, p. 37) acrescenta que "talvez a impossibilidade em encontrar uma unificação do conceito de Interdisciplinaridade" é um grande desafio pois pode estar ligada à "diversidade de contextos ao qual a palavra é aplicada, cujos principais são pesquisa, educação, empresas e mídia” (NISENBAUM apud POMBO,2017, p. 37). Nisenbaum (2017, p. 37), acrescenta que "as práticas interdisciplinares no contexto da pesquisa científica pode 
utilizar a definição de interdisciplinaridade do Dicionário Básico de Filosofia” (JAPIASSÚ, et al., 2001, p. 105), ${ }^{4}$ "correspondendo a uma nova etapa do desenvolvimento do conhecimento científico e de sua divisão epistemológica, e exigindo que as disciplinas científicas, [...], fecundem-se cada vez mais reciprocamente". Contudo, para Nisenbaum (2017):

Falar sobre interdisciplinaridade é hoje uma tarefa ingrata e difícil. Em boa verdade, quase impossível. Há uma dificuldade inicial - que faz todo o sentido ser colocada - e que tem a ver com o facto de ninguém saber o que é a interdisciplinaridade. Nem as pessoas que a praticam, nem as que a teorizam, nem aquelas que a procuram definir. A verdade é que não há nenhuma estabilidade relativamente a este conceito. Num trabalho exaustivo de pesquisa sobre a literatura existente, inclusivamente dos especialistas de interdisciplinaridade que também já os há encontram-se as mais díspares definições. Além disso, como sabem, a palavra tem sido usada, abusada e banalizada. Poderíamos mesmo dizer: a palavra está gasta. (NISENBAUM apud POMBO, 2017, p. 37)

Por outro lado, segundo o autor muitos autores que procuram uma definição para Interdisciplinaridade concordam em dois pontos: “1) existem três tipos (tríade) de relacionamento entre as disciplinas: multi ou pluridisciplinaridade, interdisciplinaridade e transdisciplinaridade; 2) o conceito de interdisciplinaridade encontra-se em posição intermediária, entre os outros dois" (NISENBAUM apud POMBO, 2017, p. 38).

Nisenbaum (2017), aponta que a interdisciplinaridade:

surge como uma espécie de "antídoto" para especialização e o clamor por esta cresceu na década de 1970, principalmente na área da educação, com muito apoio dos estudantes. De lá para cá, o trabalho interdisciplinar organizou-se "em quatro frentes: a nível discursivo, a nível de reordenamento disciplinar, de novas práticas de investigação e a nível do esforço de teorização dessas novas práticas" (NISENBAUM apud POMBO, 2017, p. 40).

Oliveira (2016), ao analisar os saberes a partir de sua pesquisa, consegue enxergar a efetividade da interdisciplinaridade entre a prática docente e a teoria de Pombo,

[...] a abertura ao saber do outro é condição sine qua non para a efetividade da interdisciplinaridade, "só é possível" se tal abertura existir. Tal assertiva está em consonância com a proposição de Pombo (2005), quando afirma que só haverá interdisciplinaridade se o profissional for capaz de partilhar o domínio do saber, se tiver a coragem necessária para abandonar o conforto da linguagem estritamente técnica e arriscar-se num domínio que é de todos e de que ninguém é proprietário exclusivo. (OLIVEIRA, apud POMBO, 2016, p. 63)

${ }^{4}$ Disponível em: http://raycydio.yolasite.com/resources/dicionario_de_filosofia_japiassu.pdf. Acesso em: 10 de novembro 2018. 
Nesta mesma toada, Soares $(2016$, p.30) aponta que a interdisciplinaridade corresponde "um modo pedagógico de integração disciplinar de viabilização do desenvolvimento de pontos de vista mais abrangentes acerca do ser humano".

Soares (2016) aponta que Pombo propõe que o argumento metafísico parte do princípio de que a interdisciplinaridade considera a "tese realista:"

cujos objetos e fatos investigados pelas várias disciplinas existem realmente, enquanto horizonte único e comum para o qual convergem todas as ciências, independentemente do fato de estarem ou não a ser investigados por nós e de nós, seres humanos, sermos ou não capazes de os conhecer adequadamente. (SOARES apud POMBO, 2016, p. 31).

A palavra "integração" é a que mais se associa a interdisciplinaridade, pois aparece no corpo das teses (SANTOS, 2017; OLIVEIRA, 2016; OTTONI, 2016; REBELLO, 2017; NOVO, 2017; GARRIDO, 2016; FREIRE, 2015; SOARES, 2016, e outras), sendo este o entendimento de Pombo.

Santos (2016) reforça o que Pombo considerou ser a palavra que mais se associa a interdisciplinaridade "integração:"

A interdisciplinaridade considera a convergência de perspectivas de disciplinas, autorizando o compartilhamento equânime de conceitos e metodologias que contribuam para a associação e percepção comum. A interdisciplinaridade procura, conjuntamente, o desenvolvimento de novos conhecimentos repousados nos movimentos disciplinares. A articulação das disciplinas, nos primórdios da modernidade, parecia improvável ou impossível de suceder, devido à dificuldade e à ausência de diálogos ocasionados pela disciplinarização, mas as ciências desenvolvidas na contemporaneidade indicam os primeiros esforços superados, apesar da permanência de dúvidas relativas à efetividade do emprego da interdisciplinaridade em pesquisas e estudos. A sua utilização deverá resguardar responsabilidades, ética e procedimentos criteriosos para refutar equívocos terminológicos devido à insipiência dos saberes (SANTOS, 2016, p. 58).

Outra observação importante apresentada por Soares (2016), está no entendimento de Pombo, quando esta se refere que a "inexistência de um conceito estável se faz presente nas práticas que 'em nome da interdisciplinaridade', rotinas estabelecidas são condenadas e abandonadas, e slogans, apelidos e hipóteses de trabalho são criados; muitas vezes eles são improvisados e mal elaborados" (SOARES, apud POMBO, 2016, p. 33).

Soares (2016), afirma que Pombo:

[...] interdisciplinaridade pode estabelecer sínteses locais, regionais, limitadas e provisórias, susceptíveis de permitir uma perspectivação compreensiva de esferas alargadas da realidade natural humana". Os limites 
das sínteses podem ser entendidos como um sintoma da "complexidade do mundo em que vivemos, um sinal e uma consequência da globalização (SOARES apud Pombo, 2016, p. 33 - 34).

Neste sentido, Soares (2016) refere-se as "Categorias de Análises e Modos de Realização Pedagógica da Integração Disciplinar", conceituada por Pombo, "constituem-se em um conjunto de categorias que permitem tipificar situações de ensino integrado, isto é, 'quaisquer situações de ensino que visem alguma articulação dos saberes disciplinares' (SOARES apud Pombo, 2016, p. 13)".

Este crescimento de áreas interdisciplinares pode estar relacionado ao fenômeno da transposição terminológica identificado por Pombo, que segundo Nisenbaum (2017) pode não ter aprofundado a discussão, mas indicou um caminho:

Neste sentido, a interdisciplinaridade, em Olga Pombo, abarca um leque conceitual amplo, se amoldando aos níveis de integração pretendidos.

\section{Contribuições da interdisciplinaridade por Olga Pombo}

Rebello (2017, p. 71) afirma que a "interdisciplinaridade surge como tema de pesquisas acadêmicas na década de 1970”, porém, segundo ele, passou a ser disseminada nas escolas e no meio acadêmico, somente no final do século XX, "através de dissertações e teses". A partir de então, o avanço na construção do conhecimento vem experimentando ritmos diferentes, conquistando expressão importante, em especial, quando impulsionado por políticas voltadas à promoção do desenvolvimento científico e tecnológico do país. (NOVO, 2017, p. 76).

Conforme explicitado por Novo (2017, p. 91), Pombo considera que a especialização dos saberes foi influenciada pela ciência moderna. A metodologia usada pela ciência moderna consistia em dividir o todo na menor parte possível para estudá-la, e depois reconstituí-la na sua totalidade. Nesta esteira "ressalta que a especialização se configura como tendência marcante da ciência moderna, em especial, a partir do século XIX e assevera que:"

[...] a ciência moderna se constitui pela adoção da metodologia analítica proposta por Galileu e Descartes. Isto é, se constituiu justamente no momento em que adotou uma metodologia que lhe permitia "esquartejar" cada totalidade, cindir o todo em pequenas partes por intermédio de uma análise cada vez mais fina. Ao dividir o todo nas suas partes constitutivas, ao subdividir cada uma dessas partes até aos seus mais ínfimos elementos, a ciência parte do princípio de que, mais tarde, poderá recompor o todo, reconstituir a totalidade. A ideia subjacente é a de que o todo é igual à soma das partes (NOVO apud POMBO, 2017, p. 91). 
Em igual sentido, Ramos (2016, p. 45) justifica a ruptura dos pressupostos até então relativos à ciência moderna no Brasil, a partir da implantação da Lei de Diretrizes e Bases da Educação Nacional no 9.394, de 20 de dezembro de 1996, estabelece que uma das finalidades previstas para a educação superior consiste no estímulo ao conhecimento dos problemas do mundo presente, sobretudo os nacionais e regionais.

Nesse sentido, Ramos (2016) aponta Pombo:

[...] não podemos recusar, nem menosprezar, nem esquecer, que foi este procedimento analítico da ciência moderna que deu origem a todos os conhecimentos e a todo o bem-estar que lhe devemos. [...]. Porém, se não podemos esquecer, diminuir, negar os benefícios da ciência moderna, tanto em termos de compreensão do mundo como de melhoria das nossas próprias vidas, isso não pode ser impeditivo do reconhecimento dos custos que a especialização trouxe consigo (RAMOS apud POMBO, 2016, p. 45).

Ramos (2016, p. 86) explica que a ideia de ciência, então, proposta por Pombo, a partir da "metáfora da rede em que não há mais um ponto fixo em que encontremos significados, posto que estamos num mundo de anulações, misturas de fronteiras, de configurações mais alargadas de conhecimento."

Acrescenta que Pombo também defende que o obstáculo nuclear da interdisciplinaridade consiste na recusa que temos ainda de perder o centro, o ponto de sentido, ou seja, de lidar com a dinâmica que a metáfora da rede propõe. E apõe que há duas direções a se pensar:

A sua faceta cognitiva, enquanto sensibilidade à complexidade, capacidade de penetração do olhar no sentido de procura de mecanismos comuns, estruturas profundas que possam articular o que aparentemente não é articulável, mas também em [2] termos de atitude: curiosidade, vontade de saber, interesse real por escutar o que o outro tem para dizer, gosto pela colaboração, pela cooperação, pelo trabalho em comum, disponibilidade para abandonar a segurança do seu domínio próprio, para irromper o confronto da sua linguagem técnica, para se aventurar em campos - lavrados por muitos, é certo - mas de que ninguém é proprietário exclusivo (RAMOS apud POMBO, 2016, p. 87).

Ramos (2016) também acrescenta a ideia de currículo defendido por Pombo quando aponta que esta revela uma tripla condição do conceito de interdisciplinaridade, ao mesmo tempo que esses fenômenos vivos na universidade orientam, muitas vezes a idealização e a operacionalização dos currículos dos cursos:

O primeiro, o sentido cognitivo que traduz como área de estudo ou campo específico de investigação. $\mathrm{O}$ segundo sentido é o normativo que refere-se a um conjunto de normas e leis que todas as instituições constituem, 
organizam e prescrevem os comportamentos dos indivíduos que a compõem. E o terceiro, o sentido escolar que consiste no "conjunto de conhecimentos que, selecionados no interior de uma ciência especializada, são considerados como devendo ser objeto de ensino numa determinada cadeira de um determinado sistema de ensino" ou estabelecimento escolar. (RAMOS apud POMBO, 2016, p. 64).

Ramos (2016, p. 64) também destaca que organizar o currículo por disciplinas é importante para que seja possível a promoção da interdisciplinaridade, sendo essencial que existam disciplinas e áreas específicas.

Neste mesmo entendimento Santos (2017) assevera que para entender o contexto das disciplinas faz-se necessário entender a 'família das disciplinas', isto é, conforme propõe Pombo:

A minha proposta é muito simples. Passa por reconhecer que, por detrás destas quatro palavras, multi, pluri, inter e transdisciplinaridade, está uma mesma raiz - a palavra disciplina. Ela está sempre presente em cada uma delas. $\mathrm{O}$ que nos permite concluir que todas elas tratam de qualquer coisa que tem a ver com as disciplinas (SANTOS apud POMBO, 2017, p. 63).

Nesta direção, Ramos (2016) citando Pombo, refere-se à interdisciplinaridade, como algo "constitutivo de flexibilidade, capacidade de adaptação, da aceitação de riscos, de aprender e agir na diversidade, aceitando novos papeis.” (RAMOS, apud POMBO, 2016, p. 202).

Segundo Ramos (2016) a interdisciplinaridade:

trata de relações não hierárquicas, com respeito pelo conhecimento do outro, pelo trabalho cooperativo, na integração de pessoas em um projeto comum, necessária para que os alunos tenham um aprofundamento amplo, suplantando a visão fragmentada de mundo. (RAMOS, 2016, p. 202).

Para o autor a interdisciplinaridade segue o entendimento da cooperação, integração e globalidade entre as diversas áreas do conhecimento científico.

\section{Considerações finais}

As teses foram utilizadas como concretizações documentadas sobre a produção do conhecimento científico pelas universidades brasileiras. A partir dos procedimentos próprios de pesquisa de revisão se chegou a uma amostra de 28 teses que utilizaram as ideias de interdisciplinaridade associada a Olga Pombo e foram estudadas para responder à pergunta: como as ideias de interdisciplinaridade pela epistemóloga portuguesa Olga Pombo tem se apresentado nas pesquisas brasileiras? 
As ideias da estudiosa portuguesa foram aplicadas a diferentes áreas: educação, saúde, desenvolvimento e meio ambiente, ciências da informação. Em uma tese, no campo da educação, a autora foi referida mais de três centenas de vezes.

Os autores das teses realizaram a integração de saberes de suas áreas com a expressão interdisciplinaridade ora expressando, interdisciplinar, ora multidisciplinar, outras transdisciplinar e também pluridisciplinar. Em todos os casos houve utilização do aparato conceitual de Olga Pombo integrando-o às problemáticas, ao campo de investigação e pesquisa que perpassaram as áreas da educação, saúde, desenvolvimento e meio ambiente, ciências da informação e nestas áreas, suas ideias foram aplicadas na formação do professor, na iniciação à docência, na pós-graduação, na educação ambiental, nas metodologias educacionais, no currículo e em fundamentos interdisciplinar.

A interdisciplinaridade de Olga Pombo traduziu-se na realização de diferentes tipos de experiências de investigação, pura e aplicada; em diferentes ambientes: em universidades, laboratórios, departamentos técnicos; educação básica, na experimentação e institucionalização de modelagem informacional e constituindo-se assim num ideário capaz de integrar e integra-se a diferentes saberes, confirmando o que a pesquisadora Olga Pombo, expressou em 2005 acerca do Brasil possuir uma longa tradição de trabalho interdisciplinar haja vista o funcionamento de mais de uma centena de programas interdisciplinares no país.

Demonstrou-se que uma educação interdisciplinar expressa um desejo de formação de pessoas que enxerguem o mundo de uma forma global, que relacionem conceitos centrais como interação, colaboração, cooperação, diálogo, contextualização, projeto conjunto. Neste sentido, o desejo expresso de compartilhamento de saberes, a partir da interdisciplinaridade aparente nas teses de diversas áreas de pesquisa, comungam dos conceitos e fundamentos de Olga Pombo, evidencia o quanto a autora vem contribuindo para essa formação interdisciplinar sem esquecer que a interdisciplinaridade, busca a interação entre diversas disciplinas e diversas áreas que juntas convergem no entendimento de ressignificar o saber através do maior ou menor compartilhamento, segundo a própria pesquisadora Olga Pombo (SANTOS apud POMBO, 2017, p.63), “é necessário reconhecer que as palavras multi, pluri, inter e transdiciplinaridade, está em uma mesma raiz - a palavra disciplina."

\section{REFERÊNCIAS}

ALMEIDA, T. M. S. A. Por "Trilhas, roteiros e legendas de uma cidade chamada Duque de Caxias: memórias e representações de Francisco Barboza Leite (1950-1990). 2017. 299 f. 
Tese (Doutorado em Humanidades, Culturas e Artes) - Universidade do Grande Rio - Prof. José de Souza Herdy, Duque de Caxias, 2017.

CONCEICAO, A. O. Interação entre universidade e empresa: a formação interdisciplinar ampla. 2016. 127 f. Tese (Doutorado em Educação) - Pontifícia Universidade Católica do Rio Grande do Sul, Porto Alegre, 2016.

COSTA, C. A. S. A Interdisciplinaridade na Produção em Educação Ambiental: Uma Leitura Ontometodológica à Luz do Materialismo Histórico-Dialético. 2015. 200 f. Tese (Doutorado em Educação Ambiental) - Universidade Federal do Rio Grande, Rio Grande, 2015.

DONATO, C. R. Dinâmica ambiental espeleológica: memória, conservação e educação. 2016. 268 f. Tese (Doutorado em Desenvolvimento e Meio Ambiente UFPI-UFRN-FUFSEUESC-UFPB/JP) - Fundação Universidade Federal de Sergipe, Natal, 2016.

FARIAS, T, C. B. Formação interdisciplinar: contribuições da residência multiprofissional em saúde. 2016. 185 f. Tese (Doutorado em Educação, Arte e História da Cultura) Universidade Presbiteriana Mackenzie, São Paulo, 2016.

FIGUEIREDO, R. O. M. Intercontextualidade na prática educativa de iniciação à docência em Matemática para a educação básica. 2017. 198 f. Tese (Doutorado em Educação em Ciências e Matemáticas) - Universidade Federal do Pará, Belém, 2017.

FREIRE, L. A. A universidade e a questão do conhecimento - o currículo acadêmico na perspectiva da inter/transdisciplinaridade e da ecologia dos saberes. 2015. $116 \mathrm{f}$. Tese (Doutorado em Educação) - Universidade Federal do Ceará, Fortaleza, 2015.

GARRIDO, L. S. A Inserção da Educação Ambiental em cursos de Pedagogia e Licenciatura em Ciências Biológicas: caminhos para a Interdisciplinaridade? 2016. 184 f. Tese (Doutorado em Ensino em Biociências e Saúde) - Fundação Oswaldo Cruz, Rio de Janeiro, 2016.

LIMA, M. H. Trajetórias de docentes nos cursos de formação: um estudo do percurso interdisciplinar e suas implicações na prática profissional. 2017. 190 f. Tese (Doutorado em Educação, Arte e História da Cultura) - Universidade Presbiteriana Mackenzie, São Paulo, 2017.

LISBOA, E. A. Inserção da interdisciplinaridade na formação de licenciandos em física. 2017. 211 f. Tese (Doutorado em Ensino, Filosofia e História das Ciências) - Universidade Federal da Bahia, Salvador, 2017.

MARTINS, C. J. V. Configurações teóricas e instrumentais para análise de informações estratégicas de aerotrópoles: um voo interdisciplinar. 2016. $313 \mathrm{f}$. Tese (Doutorado em Ciência da Informação - UFRJ - IBICT) - Universidade Federal do Rio de Janeiro, Rio de Janeiro, 2016.

MARTINS, R. O valor probatório do documento eletrônico: análise interdisciplinar entre a arquivologia e o direito. 2015. 197 f. Tese (Doutorado em Ciência da Informação) Universidade Estadual Paulista Júlio de Mesquita Filho/Marília, Marília, 2015. 
MIRANDA, S. G. Práticas de linguagem, letramentos e interdisciplinaridade em uma escola pública. 2016. 334 f. Tese (Doutorado em Letras e Linguística) - Universidade Federal de Goiás, Goiânia, 2016.

NISENBAUM, M. A. A transposição científica da física para a ciência da informação. 2017. 143 f. Tese (Doutorado em Ciência da Informação - UFRJ - IBICT) - Universidade Federal do Rio de Janeiro, Rio de Janeiro, 2017.

NOVO, L. F. Interdisciplinaridade na pesquisa: significações na cultura de uma Universidade Pública. 2017. 208 f. Tese (Doutorado em Educação) - Universidade Federal do Rio Grande do Sul, Porto Alegre, 2017.

OLIVEIRA, V. A. C. Currículo do curso de enfermagem da universidade federal de Minas Gerais: perspectiva de docentes e discentes. 2016. 125 f. Tese (Doutorado em Enfermagem) - Universidade Federal de Minas Gerais, Belo Horizonte, 2017.

OTTONI, H. M. A inovação no universo do conhecimento em ciência e tecnologia: um recorte na física experimental e aplicada. 2016. 216 f. Tese (Doutorado em Ciência da Informação UFRJ - IBICT) - Universidade Federal do Rio de Janeiro, Rio de Janeiro, 2016.

RAMOS, L. O. L. O lugar da interdisciplinaridade na educação superior: uma análise dos projetos pedagógicos dos cursos de bacharelado interdisciplinar da UFBA. 2016. 280 f. Tese (Doutorado em Educação) - Universidade Federal da Bahia, Salvador, 2016.

REBELLO, A. P. S. Ensino médio politécnico no Rio Grande do Sul: estudo das concepções teóricas e práticas pedagógicas de professores da área das ciências da natureza. 2017. 276 f. Tese (Doutorado em Educação em Ciências e Matemática) - Pontifícia Unidade Católica do Rio Grande do Sul, Porto Alegre, 2017.

SANTOS, C. D. Ciência da informação e interdisciplinaridade: interconexões com a cultura informacional. 2017. 262 f. Tese (Doutorado em Ciência da Informação) Universidade Estadual Paulista Júlio de Mesquita Filho/Marília, Marília, 2017.

SANTOS, J. C. S. A informação em instituições políticas: subsídios teóricos e empíricos à proposição do modelo de comportamento informacional em assessorias parlamentares. 2016. 215 f. Tese (Doutorado em Ciência da Informação) - Universidade Federal da Bahia, Salvador, 2016.

SOARES, J. M. Integração disciplinas na voz dos docentes de Física, Biologia e Química do Colégio Estadual Ernesto de Farias, São Cristóvão-RJ. 2016. 261 f. Tese (Doutorado em Química Biológica) - Universidade Federal do Rio de Janeiro, Rio de Janeiro, 2016.

SOUZA, R. S. A trajetória da política de integração em um curso de enfermagem de uma universidade pública: um estudo de caso. 2016. $124 \mathrm{f}$. Tese (Doutorado em Enfermagem) - Universidade Federal de Minas Gerais, Belo Horizonte, 2016.

VERDUM, P. L. Formação inicial de professores para educação básica, no contexto dos IFs: propondo indicadores de qualidade, a partir de um estudo de caso no IFRS. 2015. $281 \mathrm{f}$. Tese (Doutorado em Educação) - Pontifícia Universidade Católica do Rio Grande do Sul, Porto Alegre, 2015. 
VILARINHO, T. F. Padrões de comunicação científica nas ciências sociais: a interdisciplinaridade entre economia, ciência política, sociologia e antropologia. 2015. $220 \mathrm{f}$. Tese (Doutorado em Ciências da Informação) - Universidade de Brasília, Brasília, 2015.

WERLANG, R. B. Geoilhas: o ensino de geociências na educação básica articulado com a ilha interdisciplinar de racionalidade. 2017. 168 f. Tese (Doutorado em Educação em Ciências Químicas da Vida e Saúde UFSM - FURG) - Universidade Federal do Rio Grande do Sul, Porto Alegre, 2017.

XAVIER, A. M. Flexibilidade curricular, Interdisciplinaridade e Formação continuada: Projeto Mol(ecul)ar de Formação Superior da UFABC. 2015. 219 f. Tese (Doutorado em Ciência e Tecnologia) - Universidade Federal do ABC, Santo André, 2015.

ZIMMERMANN, J. M. Da representação da imagem à imagem como representação em O Pintor de Retratos e Satolep. 2016. 175 f. Tese (Doutorado em Letras) - Universidade Federal do Rio Grande do Sul, Porto Alegre, 2016.

\section{Como citar este artigo:}

MEDINA, Patrícia; PEREIRA, Maria Leda Melo Lustosa; PAIVA, José Rudacy Feijó. Estudo da ciência da educação fundamentada na interdisciplinaridade por Olga Pombo: um estudo de revisão. Revista Ibero-Americana de Estudos em Educação, Araraquara, v. 14, n. $\quad 4, \quad$ p. 2287-2300, out./dez., 2019. e-ISSN: 1982-5587. DOI: https://doi.org/10.21723/riaee.v14i4.12113

Data de Submissão: 25/01/2019

Revisões requeridas: 22/03/2019

Aceite em: 20/05/2019

Publicado em: 02/09/2019 